\title{
Women's Experiences with and Preference for Induction of Labor with Oral Misoprostol or Foley Catheter at Term
}

Mieke L.G. ten Eikelder, MD ${ }^{1}$ Marieke M. van de Meent, MD ${ }^{1}$ Kelly Mast, MD² Katrien Oude Rengerink, $\mathrm{PhD}^{3}$ Marta Jozwiak, $\mathrm{MD}^{1} \quad$ Irene M. de Graaf, $\mathrm{MD}^{3}$ Marloes A. G. Holswilder-Olde Scholtenhuis, MD ${ }^{4}$ Frans J. M. E. Roumen, MD ${ }^{5}$ Martina M. Porath, MD Aren J. van Loon, $\mathrm{MD}^{7}$ Eline S. van den Akker, $\mathrm{MD}^{8}$ Robbert J. P. Rijnders, $\mathrm{MD}^{9}$ A. Hanneke Feitsma, MD ${ }^{10}$ Albert H. Adriaanse, MD ${ }^{11}$ Moira A. Muller, MD ${ }^{12}$ Jan W. de Leeuw, MD ${ }^{13}$ Harry Visser, MD ${ }^{14}$ Mallory D. Woiski, MD ${ }^{15}$ Sabina Rombout-de Weerd, MD ${ }^{16}$ Gijs A. van Unnik, MD ${ }^{17}$ Paula J. M. Pernet, MD ${ }^{18}$ Hans Versendaal, MD ${ }^{19}$ Ben W. Mol, PhD ${ }^{20}$ Kitty W. M. Bloemenkamp, PhD ${ }^{21}$

${ }^{1}$ Department of Obstetrics, Leiden University Medical Center, Leiden, The Netherlands

${ }^{2}$ Department of Obstetrics and Gynecology, Maastricht Medical Center, Maastricht, The Netherlands

3 Julius Center for Health Sciences and Primary Care, University Medical Center Utrecht, Utrecht, The Netherlands

${ }^{4}$ Department of Obstetrics and Gynecology, University Medical Center Groningen, Groningen, The Netherlands

${ }^{5}$ Department of Obstetrics and Gynecology, Zuyderland Medical Center, Heerlen, The Netherlands

${ }^{6}$ Department of Obstetrics and Gynecology, Maxima Medical Center, Veldhoven, The Netherlands

${ }^{7}$ Department of Obstetrics and Gynecology, Martini Hospital, Groningen, The Netherlands

8 Department of Obstetrics and Gynecology, OLVG Oost, Amsterdam, The Netherlands

${ }^{9}$ Department of Obstetrics and Gynecology, Jeroen Bosch Hospital, 's-Hertogenbosch, The Netherlands

10 Department of Obstetrics and Gynecology, HAGA Hospital, Den Haag, The Netherlands

${ }^{11}$ Department of Obstetrics and Gynecology, Noordwest Ziekenhuisgroep, Alkmaar, The Netherlands

12 Department of Obstetrics and Gynecology, Spaarne Hospital, Hoofddorp, The Netherlands
Address for correspondence Mieke L.G. ten Eikelder, MD, Department of Obstetrics, K-6 P-35, Leiden University Medical Center, P.O. Box 9600, 2300 RC Leiden, The Netherlands (e-mail: m.teneikelder@gmail.com).

${ }^{13}$ Department of Obstetrics and Gynecology, Ikazia Hospital, Rotterdam, The Netherlands

${ }^{14}$ Department of Obstetrics and Gynecology, Ter Gooi Hospital, Hilversum, The Netherlands

${ }^{15}$ Department of Obstetrics and Gynecology, Radboud University Medical Center, Nijmegen, The Netherlands

${ }^{16}$ Department of Obstetrics and Gynecology, Albert Schweitzer Hospital, Dordrecht, The Netherlands

${ }^{17}$ Department of Obstetrics and Gynecology, Diaconessenhuis, Leiden, The Netherlands

${ }^{18}$ Department of Obstetrics and Gynecology, Kennemer Gasthuis, Haarlem, The Netherlands

${ }^{19}$ Department of Obstetrics and Gynecology, Maasstad Hospital, Rotterdam, The Netherlands

${ }^{20}$ The Robinson Research Institute, University of Adelaide, Adelaide, South Australia, Australia

${ }^{21}$ Division Women and Baby, Department of Obstetrics, Birth Centre, University Medical Centre Utrecht, Utrecht, The Netherlands Am J Perinatol 2017;34:138-146.

Abstract

received

March 14, 2016 accepted after revision May 4, 2016 published online June 24, 2016
Objective We assessed experience and preferences among term women undergoing induction of labor with oral misoprostol or Foley catheter.

Study Design In 18 of the 29 participating hospitals in the PROBAAT-II trial, women were asked to complete a questionnaire within 24 hours after delivery. We adapted a validated questionnaire about expectancy and experience of labor and asked women whether they would prefer the same method again in a future pregnancy. 


\section{Keywords}

- induction of labor

- oral misoprostol

- Foley catheter

- patient experience

- patient preference
Results The questionnaire was completed by 502 (72\%) of 695 eligible women; 273 (54\%) had been randomly allocated to oral misoprostol and 229 (46\%) to Foley catheter. Experience of the duration of labor, pain during labor, general satisfaction with labor, and feelings of control and fear related to their expectation were comparable between both the groups. In the oral misoprostol group, $6 \%$ of the women would prefer the other method if induction is necessary in future pregnancy, versus $12 \%$ in the Foley catheter group (risk ratio: 0.70 ; $95 \%$ confidence interval: $0.55-0.90 ; p=0.02$ ).

Conclusion Women's experiences of labor after induction with oral misoprostol or Foley catheter are comparable. However, women in the Foley catheter group prefer more often to choose a different method for future inductions.
Currently, 20 to $30 \%$ of all deliveries are induced. ${ }^{1-3}$ Induction is a solid option when the outcome for mother and child is likely to be improved by delivering the baby rather than continuing the pregnancy. Common indications for induction of labor are postterm pregnancy, hypertensive disorders, prelabor rupture of membranes, diabetes in pregnancy, suspected intrauterine growth restriction, macrosomia, and elective reasons. ${ }^{4,5}$

Most research regarding induction of labor has focused on methods and different management strategies, with little attention for women's experiences and preferences. ${ }^{6,7}$ In a prospective cohort study among 936 women, those who had their labor induced had a less positive birth experience compared with spontaneous labor (odds ratio [OR]: 1.5; 95\% confidence interval $[\mathrm{CI}]: 1.0-2.3) .^{5}$ Also, women who had their labor induced were less satisfied with the care received compared with women who had spontaneous onset of labor. ${ }^{8}$

In women with an unripe cervix requiring induction of labor, both oral misoprostol and the Foley catheter are safer than vaginal prostaglandins. ${ }^{6-9}$ Our recent PROBAAT-II trial compared induction of labor with $50-\mu$ g oral misoprostol to $30-\mathrm{mL}$ transcervical Foley catheter in women with an unfavorable cervix at term. The study showed that induction with oral misoprostol was comparable to Foley catheter in terms of safety and effectiveness. ${ }^{9}$ With a comparable safety and effectiveness profile, women's experiences and preferences will become increasingly important.

As women's experiences and preferences for induction of labor with oral misoprostol or Foley catheter have not been compared, we evaluated women's experiences, general satisfaction, and preferences after induction of labor with oral misoprostol or Foley catheter at term.

\section{Materials and Methods}

\section{Study Design}

This study was conducted as part of the PROBAAT-II trial (registered in the Netherlands trial register, number NTR3466). The PROBAAT-II trial compared term induction of labor with oral misoprostol to Foley catheter in 29 hospitals in the Netherlands. In 18 of the 29 participating hospitals, participating women were requested to complete a questionnaire on their labor experience within 24 hours after delivery. These 18 hospitals were selected because trained research staff was available to handle the questionnaires, thus ensuring quality. All questionnaires were anonymous and all women gave written informed consent. The Medical Ethics Committee (MEC) of Amsterdam Medical Center in Amsterdam and the institutional review boards of participating hospitals approved the study protocol, including the women's experience and preference questionnaire, before start of the study (MEC 11/010).

\section{Participants and Procedures}

Details of the study protocol have been reported elsewhere. ${ }^{9}$ In short, the trial was a multicenter open-label randomized controlled trial studying women with a viable singleton pregnancy beyond 37 weeks of gestation, scheduled for induction of labor, with an unfavorable cervix (Bishop score $<6$ ) and without a previous cesarean section. The study compared induction of labor with oral misoprostol to Foley catheter. Women in the oral misoprostol group were treated

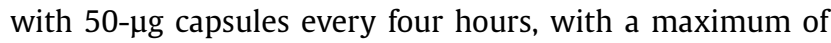
three doses in 24 hours. In the Foley catheter group, a 30-mL Foley catheter filled with $0.9 \%$ sodium chloride or sterile water was placed. The placement was either digital or using a speculum, depending on the preferences of the treating physician. All patients were admitted to the hospital from start induction until delivery. If upon examination, the cervix was found to be favorable (Bishop score $\geq 6$ ), amniotomy was performed and oxytocin infusion was started, if needed, in both groups.

\section{Outcomes}

Women were informed about the study by their attending obstetrician or midwife and received a brochure at least 1 day before admission. This brochure contained information about the purpose of the study, implication of participation, and possible side effects of the induction methods. When consent to participation was given and randomization had taken place, women received the questionnaire within 24 hours 
after delivery. Thereafter, they were asked to complete the questionnaire within the following 24 hours.

The main outcome was listing women's experiences with the method used for induction of labor. Secondary outcomes included preferences and pain perception during labor, the source of knowledge about induction of labor, and whether the information provided was sufficient.

Currently, there is no availability of validated questionnaires on experiences of and preferences for induction of labor. We therefore modified a validated questionnaire by Wijma et al concerning delivery expectancy and experiences..$^{10,11}$ We extrapolated a set of 11 questions regarding moods and experiences with answers on a scale of 1 to 5 ("Much worse than expected," "Worse than expected," "As expected," "Better than expected," and "Much better than expected") and an option to fill in "Don't know." Pain perception by women was measured on a visual analog scale (VAS) ranging from 0 to 100 . As it is not easy to distinguish between the ripening phase and the active phase of labor, we decided to ask the questions as an overall experience. It is not feasible to give both induction methods to the same woman for the same pregnancy and then ask which she would prefer. Therefore, to evaluate the preference for the induction method, we asked if they felt like the alternative procedure of induction of labor would have been better for them. At the end of the questionnaire, there was a free text field for comments and questions. The questionnaires were administered in Dutch and translated in English for purpose of this article (-Supplementary Appendix, available in the online version).

\section{Statistical Analysis}

Normally distributed continuous data are shown as means with standard deviations and skewed distributions as medians with interquartile ranges. Percentage calculation was based on the number of available observations. Univariate and multivariate analyses were performed for the induction method preference question, adjusting for mode of delivery, time to delivery, analgesic use, and admission postpartum. The estimated effect of the comparison is shown as OR with $95 \% \mathrm{Cl}$. For the analysis of the mood and experiences questions, we combined the "Much worse than expected" and "Worse than expected," as well as the answers "Better than expected" and "Much better than expected." Thereby, we had a trichotomous outcome and compared each question between the two induction methods.

To explore the relation between the categorical variables of both groups, we used the chi-square test for Fisher's exact test, where appropriate. For nonnormally distributed continuous data, we used the Mann-Whitney's $U$ test. We performed all statistical analyses using SPSS (IBM SPSS Statistics for Mac, version 22.0, SPSS Inc.). We considered a $p$-value of $<0.05$ to indicate statistically significance.

\section{Results}

Between July 2012 and October 2013, 1,859 women were randomized in the PROBAAT-II trial. From these, we selected 18 hospitals to participate in the women's experience and questionnaires trial (1,200 women). The experience and questionnaires trial was implemented alongside the PROBAAT-II trial in March 2013. This yielded 695 women eligible to fill out the questionnaire. Of them, $502(72 \%)$ women participated, of which 273 (54\%) were allocated to oral misoprostol and 229 (46\%) to a Foley catheter (-Fig. 1).

Baseline demographic and clinical characteristics were comparable between the oral misoprostol and Foley catheter groups (-Table $\mathbf{1}$ ). The most frequent indications for induction of labor were hypertensive disorders and postterm pregnancy. When we compared responders to nonresponders, we had more responses from Caucasian women (81 vs. $69 \%, p=0.04$ ). Elective reasons for induction (defined as pelvic instability, social or psychosocial, macrosomia, gestational diabetes with diet and without medication, obstetric history) were less frequent among the responders group versus the nonresponders ( 22 vs. $31 \%, p=0.05$ ). Other characteristics such as mode of delivery, analgesic use, postpartum bleeding, neonatal morbidity, and admission postpartum did not differ between responders and nonresponders (-Table $\mathbf{1}$ ).

Most participating women (96\%) stated that the information received before induction about the induction of labor process was sufficient. Most information was given by gynecologists ( $74 \%$ of all participating women), followed by brochures ( $18 \%$ of all participating women) and midwives ( $17 \%$ of all participating women).

In the comparison between the oral misoprostol and Foley catheter groups, we found no significant difference in what women reported about the duration of labor, pain perception and emotions during labor, and the feeling of control compared with what they expected (-Table 2 ). The overall satisfaction for the total procedure was also comparable between the groups ( - Table 2 ).

The VAS scores for pain during labor were comparable (median of 80 in both groups, $p=0.29$ ).

In the oral misoprostol group, $16(6 \%)$ of 273 women would prefer the other method for future inductions, while in the Foley catheter group, this were $27(12 \%)$ of 229 women (risk ratio: 0.70; 95\%CI: 0.55-0.90; p: 0.02) (-Fig. 2). Multivariate analyses showed that the women preferring to switch to the alternative method in future pregnancies were not influenced by mode of delivery, time from randomization to delivery, the use of analgesics and admission postpartum. There were no differences in responses of women between the participating hospitals (data not shown).

Seventeen women reported a comment in the open text field; two women in the oral misoprostol group reported early contractions and hyperstimulation. In the Foley group, four women described a painful placement of the Foley catheter and seven women reported the duration of labor to be too long and had expected to give birth within a day.

\section{Comment}

To our knowledge, this is the first evaluation that compared women's experiences and preferences with oral misoprostol 


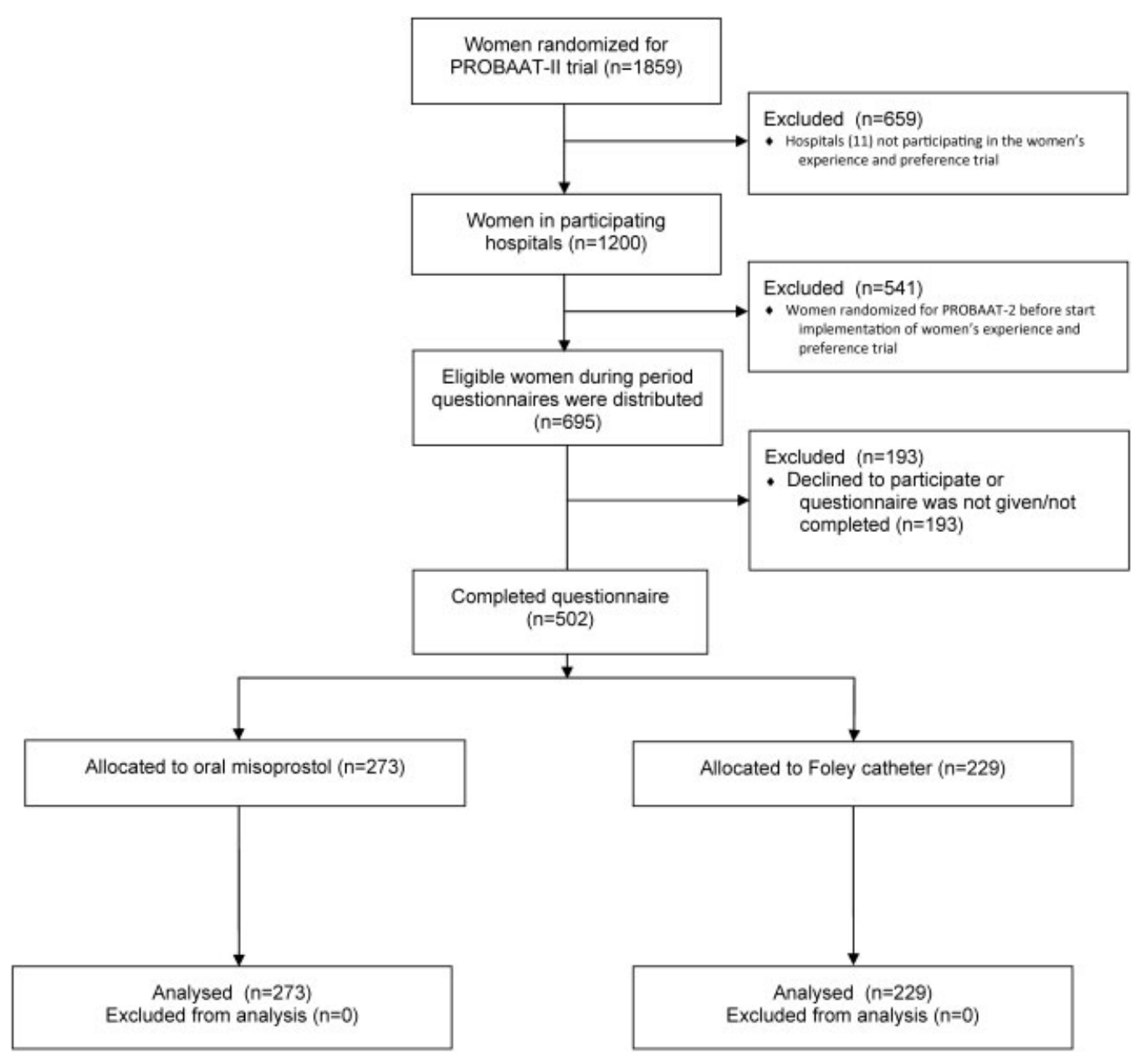

Fig. 1 Flowchart.

or Foley catheter for induction of labor. Most women were satisfied with the information received. Experience of the duration of labor, general satisfaction with labor, and feelings of control and fear related to expectation, as well as pain perception were comparable in both groups. More women in the Foley catheter group (vs. the oral misoprostol group) would prefer an alternative method if induction would be required in a future pregnancy.

This study is not without limitations. Unfortunately, until now there are no validated questionnaires on women's experience and preferences for different methods of cervical ripening for induction of labor. Therefore, we adapted a validated questionnaire about expectancy and experience of labor by Wijma et al. ${ }^{10,11}$ This provides the possibility that the questionnaire did not measure what it is supposed to measure. Furthermore, women were asked about or reported their experience of the whole procedure, and not only their experience of the cervical ripening. Since completion of a questionnaire is difficult during the active phase of labor, and because determination of the active phase is not realizable, we assume this to be the best solution. Another limitation of the questionnaire is that we did not include the question why women would prefer the other method of induction of labor in future pregnancy. Previous reports showed that most relevant domains for women's overall experience of labor are the availability and quality of (emotional) care received during labor, worries about the baby's health and safety, and the experience of duration until the first contact with the newborn. ${ }^{12,13}$ We would advise to include these elements in a future questionnaire to achieve a better birth-specific outcome measure.

Of the women asked to fill out the questionnaire, $72 \%$ completed the questionnaire. Only women who were able to complete the questionnaire in Dutch could participate in the study and that is possibly the reason why more non-Caucasians have not answered the questionnaire or were not asked to fill in the questionnaire. Previous papers ${ }^{14-16}$ suggested that there is a need to improve the information provided on the reasons and the procedure of labor induction to reduce unrealistic expectations. In our trial, almost all women were satisfied with the information received. The fact that the health care providers were aware of the questionnaire might have influenced the outcome by giving more information and/or attention to the women.

More women in the Foley catheter group would prefer induction with the alternative method (oral misoprostol) in future pregnancies. Multivariate analysis showed that other factors such as mode of delivery, time to delivery, the use of analgesics, and admission postpartum had no influence on the outcome for the wish to switch between 
142 Women's Experiences with and Preference for Induction of Labor ten Eikelder et al.

Table 1 Baseline demographics and clinical characteristics

\begin{tabular}{|c|c|c|c|c|c|}
\hline \multirow[t]{2}{*}{ Characteristic } & \multicolumn{2}{|c|}{ Responders $(n=502)$} & \multicolumn{2}{|c|}{ Nonresponders $(n=193)$} & \multirow{2}{*}{$\begin{array}{l}\text { P-Value responders } \\
\text { vs. nonresponders }\end{array}$} \\
\hline & $\begin{array}{l}\text { Oral misoprostol } \\
(n=273)\end{array}$ & $\begin{array}{l}\text { Foley catheter } \\
(n=229)\end{array}$ & $\begin{array}{l}\text { Oral misoprostol } \\
(n=90)\end{array}$ & $\begin{array}{l}\text { Foley catheter } \\
(n=103)\end{array}$ & \\
\hline Maternal age (years; mean [SD]) & $31.1(4.8)$ & $30.6(4.7)$ & $30.5(6.0)$ & $30.1(4.8)$ & $0.52^{\wedge}$ \\
\hline Ethnic origin (\%) & & & & & 0.04 \\
\hline Caucasian & $218(79.9 \%)$ & $186(81.2 \%)$ & $67(74.4 \%)$ & $78(75.7 \%)$ & \\
\hline Other & $55(20.1 \%)$ & $43(18.8 \%)$ & $23(25.6 \%)$ & $25(24.3 \%)$ & \\
\hline $\begin{array}{l}\text { Body mass index (median } \\
{[\mathrm{IQR}] \text { ) }}\end{array}$ & $25.4(22.3-29.8)^{\mathrm{a}}$ & $24.4(21.8-28.7)^{\mathrm{b}}$ & $25.2(22.6-29.1)^{c}$ & $24.9(22.0-30.3)^{d}$ & $0.84^{\wedge}$ \\
\hline Parity & & & & & 0.83 \\
\hline 0 & $177(64.8 \%)$ & $133(58.1 \%)$ & $56(62.2 \%)$ & $66(64.1 \%)$ & \\
\hline 1 & $64(23.4 \%)$ & $70(30.6 \%)$ & $24(26.7 \%)$ & $28(27.2 \%)$ & \\
\hline$\geq 2$ & $32(11.7 \%)$ & $26(11.4 \%)$ & $10(11.1 \%)$ & $9(8.7 \%)$ & \\
\hline $\begin{array}{l}\text { Gestational age } \\
\text { (weeks; median [IQR]) }\end{array}$ & $39.2(38.1-41.0)$ & $39.3(38.2-41.1)$ & $39.3(38.1-40.6)$ & $39.6(38.2-41.0)$ & $0.92^{\wedge}$ \\
\hline Bishop score (median [IQR]) & $2.0(1.0-3.0)^{\mathrm{e}}$ & $2.0(1.0-3.0)^{f}$ & $2.0(1.0-3.0)^{9}$ & $2.0(1.0-3.0)^{\mathrm{h}}$ & $0.58^{\wedge}$ \\
\hline \multicolumn{6}{|l|}{ Indication for induction } \\
\hline Hypertensive disorders & $93(34.1 \%)$ & $78(34.1 \%)$ & $35(38.9 \%)$ & $26(25.2 \%)$ & 0.54 \\
\hline Postterm pregnancy & $73(26.7 \%)$ & $66(28.8 \%)$ & $19(21.1 \%)$ & $29(28.2 \%)$ & 0.45 \\
\hline Insulin dependent diabetes & $16(5.9 \%)$ & $10(4.4 \%)$ & $7(7.8 \%)$ & $10(9.7 \%)$ & 0.08 \\
\hline Oligohydramnios & $10(3.7 \%)$ & $10(4.4 \%)$ & $4(4.4 \%)$ & $6(5.8 \%)$ & 0.49 \\
\hline $\begin{array}{l}\text { Intra uterine growth } \\
\text { restriction }\end{array}$ & $20(7.3 \%)$ & $18(7.9 \%)$ & $6(6.7 \%)$ & $5(4.9 \%)$ & 0.39 \\
\hline Obstetric cholestasis & $9(3.3 \%)$ & $4(1.7 \%)$ & $1(1.1 \%)$ & $1(1.0 \%)$ & $0.17^{*}$ \\
\hline Decreased fetal movements & $25(9.2 \%)$ & $25(10.9 \%)$ & $9(10.0 \%)$ & $11(10.7 \%)$ & 0.88 \\
\hline Elective\# & $62(22.7 \%)$ & $50(21.8 \%)$ & $30(33.3 \%)$ & $29(28.2 \%)$ & 0.05 \\
\hline Other & $23(8.4 \%)$ & $21(9.2 \%)$ & $6(6.7 \%)$ & $10(9.7 \%)$ & 0.84 \\
\hline \multicolumn{6}{|l|}{ Fetal gender } \\
\hline Male gender & $142(52.0 \%)$ & $125(54.6 \%)$ & $43(42.6 \%)$ & $58(57.4 \%)$ & 0.84 \\
\hline \multicolumn{6}{|l|}{ Hyperstimulation } \\
\hline With FHR changes & $5(1.8 \%)$ & $5(2.2 \%)$ & $6(6.7 \%)$ & $2(1.9 \%)$ & 0.11 \\
\hline Without FHR changes & $2(0.7 \%)$ & $4(1.7 \%)$ & $1(1.1 \%)$ & $1(1.0 \%)$ & 0.86 \\
\hline \multicolumn{6}{|l|}{ Mode of delivery } \\
\hline Spontaneous & $193(70.7 \%)$ & $171(74.7 \%)$ & $56(62.2 \%)$ & $75(72.8 \%)$ & 0.23 \\
\hline Vaginal instrumental & $37(13.6 \%)$ & $19(8.3 \%)$ & $9(10.0 \%)$ & $8(7.8 \%)$ & 0.37 \\
\hline Cesarean section & $43(15.8 \%)$ & $39(17.0 \%)$ & $25(27.8 \%)$ & $20(19.4 \%)$ & 0.03 \\
\hline $\begin{array}{l}\text { Time induction to birth } \\
\text { (h; median [IQR]) }\end{array}$ & $30(17-50)$ & $30(22-37)$ & $31(17-59)$ & $32(22-54)$ & $0.12^{\wedge}$ \\
\hline \multicolumn{6}{|l|}{ Analgesics use } \\
\hline None & $85(31.1 \%)$ & $58(25.3 \%)$ & $21(23.3 \%)$ & $23(22.3 \%)$ & 0.13 \\
\hline $\begin{array}{l}\text { Pethidine/phenergan/nubain/ } \\
\text { remifentanil }\end{array}$ & $59(21.6 \%)$ & $53(23.1 \%)$ & $14(15.6 \%)$ & $23(22.3 \%)$ & 0.37 \\
\hline Epidural & $112(41.0 \%)$ & $104(45.4 \%)$ & $43(47.8 \%)$ & $51(49.5 \%)$ & 0.18 \\
\hline $\begin{array}{l}\text { Postpartum bleeding } \geq 1000 \\
\mathrm{~mL}\end{array}$ & $30(11.0 \%)$ & $17(7.4 \%)$ & $3(3.3 \%)$ & $11(10.7 \%)$ & 0.38 \\
\hline $\begin{array}{l}\text { Postpartum } \\
\text { bleeding } \geq 500 \mathrm{cc}\end{array}$ & 87 (31.9\%) & $63(27.5 \%)$ & $28(31.1 \%)$ & $21(20.4 \%)$ & 0.24 \\
\hline \multicolumn{6}{|l|}{ Apgar score $<7$} \\
\hline $1 \mathrm{~min}$ & $15(5.5 \%)$ & $10(4.4 \%)$ & $7(2.6 \%)$ & $5(2.2 \%)$ & 0.52 \\
\hline $5 \mathrm{~min}$ & $7(2.6 \%)$ & $5(2.2 \%)$ & $2(2.2 \%)$ & $3(2.9 \%)$ & $1.00^{*}$ \\
\hline \multicolumn{6}{|l|}{ Umbilical cord arterial pH } \\
\hline $\mathrm{pH} \leq 7.05$ & $4(1.9 \%)^{i}$ & $3(1.8 \%)^{j}$ & $4(6.5 \%)^{k}$ & $3(4.0 \%)^{1}$ & $0.06^{*}$ \\
\hline
\end{tabular}


Table 1 (Continued)

\begin{tabular}{|c|c|c|c|c|c|}
\hline \multirow[t]{2}{*}{ Characteristic } & \multicolumn{2}{|c|}{ Responders $(n=502)$} & \multicolumn{2}{|c|}{ Nonresponders $(n=193)$} & \multirow{2}{*}{$\begin{array}{l}P \text {-Value responders } \\
\text { vs. nonresponders }\end{array}$} \\
\hline & $\begin{array}{l}\text { Oral misoprostol } \\
(n=273)\end{array}$ & $\begin{array}{l}\text { Foley catheter } \\
(n=229)\end{array}$ & $\begin{array}{l}\text { Oral misoprostol } \\
(n=90)\end{array}$ & $\begin{array}{l}\text { Foley catheter } \\
(n=103)\end{array}$ & \\
\hline $\mathrm{pH} \leq 7.10$ & $14(6.6 \%)^{m}$ & $12(7.1 \%)^{n}$ & $6(9.7 \%)^{\circ}$ & $5(6.7 \%)^{p}$ & 0.63 \\
\hline \multicolumn{6}{|l|}{ Maternal admission } \\
\hline Ward & $147(53.8 \%)$ & $119(52.0 \%)$ & $46(51.1 \%)$ & $52(50.5 \%)$ & 0.60 \\
\hline Medium care & $2(0.7 \%)$ & $4(1.7 \%)$ & $1(1.1 \%)$ & $1(1.0 \%)$ & $1.00^{*}$ \\
\hline Intensive care & $0(0.0 \%)$ & $0(0.0 \%)$ & $0(0.0 \%)$ & $0(0.0 \%)$ & NA \\
\hline \multicolumn{6}{|l|}{ Neonatal admission } \\
\hline Ward & $85(31.1 \%)$ & $66(28.8 \%)$ & $26(28.9 \%)$ & $30(29.1 \%)$ & 0.78 \\
\hline Medium care & 35 (12.8\%) & $29(12.7 \%)$ & $13(14.4 \%)$ & $16(15.5 \%)$ & 0.43 \\
\hline Intensive care & $8(2.9 \%)$ & $13(5.7 \%)$ & $6(6.7 \%)$ & $6(5.8 \%)$ & 0.26 \\
\hline $\begin{array}{l}\text { Neonatal death }(<28 \text { days } \\
\text { postpartum) }\end{array}$ & $0(0 \%)$ & $1(0.4 \%)$ & $0(0.0 \%)$ & $0(0 \%)$ & $1.00^{*}$ \\
\hline
\end{tabular}

Abbreviations: FHR, fetal heart rate; IQR, interquartile range; SD, standard deviation.

a $9 \%$ (25 of 273 women) missing.

${ }^{\mathrm{b}} 4 \%$ (10 of 229 women) missing.

${ }^{\mathrm{c}} 7.8 \%$ (7 of 90 women) missing.

d $8.7 \%$ ( 9 of 103 women) missing.

e $33 \%$ (89 of 273 women) missing.

$f_{35 \%}$ (81 of 229 women) missing.

${ }^{9} 33 \%$ (30 of 90 women) missing.

h $40 \%$ (41 of 103 women) missing.

i $44 \%$ (120 of 273 women) missing.

$\mathrm{j}_{52 \%}$ (120 of 229 women) missing.

$\mathrm{k}_{31 \%}$ (28 of 90 women) missing.

'27\% (28 of 103 women) missing.

$\mathrm{m}_{44 \%}$ (120 of 273 women) missing.

${ }^{\mathrm{n}} 52 \%$ (120 of 229 women missing).

०31\% (28 of 90 women) missing.

P27\% (28 of 103 women) missing.

\#Pelvic instability, social or psychosocial reasons, macrosomia, gestational diabetes mellitus with diet, obstetric history.

^Mann-Whitney $U$ test.

*Fisher's exact test.

Foley catheter and oral misoprostol in future pregnancy if induction would be necessary. Furthermore, only two women had experience with induction of previous pregnancies; therefore, this had no influence on the overall results. Taken together, other factors should be at hand. An explanation for the difference could be that women experienced discomfort or pain during the placement or after insertion of the Foley catheter, as was described several times in the answers of the open text field. Jonsson et $\mathrm{al}^{17}$ showed that women could experience placement of the Foley catheter past the internal os of the cervix as painful. Furthermore, they address digital placement of the Foley catheter as less painful than insertion with the use of a speculum. Both methods were used in this study, but unfortunately the used method was not recorded. In one study comparing Foley catheter to $25-\mu \mathrm{g}$ vaginal misoprostol, 104 women were asked postpartum about their discomfort level regarding the induction method on a VAS. Five (10\%) of the women reported discomfort during Foley placement versus none of the women receiving vaginal misoprostol. ${ }^{15}$ Another study performed a structured interviewer-administered questionnaire after the cervical ripening process on 90 women and found that significantly more women felt discomfort during cervical ripening with the Foley catheter compared with vaginal misoprostol (93 vs. 62\%; $p<0.001$ ). They did not find differences in the likelihood to choose the same method of cervical ripening for possible future inductions (91 vs. 100\%; $p=0.08) .{ }^{18}$ Another explanation could be that more vaginal examinations were performed in the oral misoprostol group (mean: 8.1 vs. 6.8 ), thereby creating more contact moments with the attending physician that could lead to more satisfaction with the induction experience instead of the previously assumed disadvantage of vaginal examinations. Different cultural perceptions of induction of labor might influence the preference for an induction method. Therefore, further research is needed to generalize these results to other countries or ethnicity groups.

All women were admitted to a hospital for the ripening process during the study period. In several countries 
Table 2 General satisfaction for the whole induction and delivery procedure

\begin{tabular}{|c|c|c|c|c|c|c|c|}
\hline \multirow[t]{2}{*}{ Question } & \multicolumn{3}{|c|}{ Oral misoprostol $(n=273)$} & \multicolumn{3}{|c|}{ Foley catheter $(n=229)$} & \multirow[t]{2}{*}{$P$-Value } \\
\hline & $\begin{array}{l}\text { Worse than } \\
\text { expected }\end{array}$ & $\begin{array}{l}\text { As } \\
\text { expected }\end{array}$ & $\begin{array}{l}\text { Better than } \\
\text { expected }\end{array}$ & $\begin{array}{l}\text { Worse than } \\
\text { expected }\end{array}$ & $\begin{array}{l}\text { As } \\
\text { expected }\end{array}$ & $\begin{array}{l}\text { Better than } \\
\text { expected }\end{array}$ & \\
\hline $\begin{array}{l}\text { What did you think of the } \\
\text { duration of the labor? }\end{array}$ & 79 (30.9\%) & $59(23.0 \%)$ & $118(46.1 \%)^{a}$ & $56(25.7 \%)$ & $48(22.0 \%)$ & $114(52.3 \%)^{b}$ & 0.35 \\
\hline $\begin{array}{l}\text { How did you experience } \\
\text { the pain during the labor? }\end{array}$ & $123(59.7 \%)$ & $50(24.3 \%)$ & $33(16.0 \%)^{c}$ & $100(55.6 \%)$ & $55(30.6 \%)$ & $25(13.9 \%)^{d}$ & 0.37 \\
\hline $\begin{array}{l}\text { How did you experience } \\
\text { the labor in general? }\end{array}$ & $126(48.5 \%)$ & 75 (28.8\%) & $59(22.7 \%)^{\mathrm{e}}$ & $91(42.1 \%)$ & $59(27.3 \%)$ & $66(30.6 \%)^{f}$ & 0.14 \\
\hline $\begin{array}{l}\text { Did you panic during the } \\
\text { labor? }\end{array}$ & $98(37.8 \%)$ & $81(31.3 \%)$ & $80(30.9 \%)^{9}$ & $81(38.0 \%)$ & $57(26.8 \%)$ & $75(35.2 \%)^{h}$ & 0.48 \\
\hline $\begin{array}{l}\text { Did you feel strong during } \\
\text { the labor? }\end{array}$ & $73(28.3 \%)$ & $110(42.6 \%)$ & $75(29.1 \%)^{i}$ & $52(23.7 \%)$ & $98(44.7 \%)$ & $69(31.5 \%)^{j}$ & 0.53 \\
\hline $\begin{array}{l}\text { Were you happy during the } \\
\text { labor }\end{array}$ & $58(24.3 \%)$ & $96(40.2 \%)$ & $85(35.6 \%)^{k}$ & $33(16.6 \%)$ & $90(45.2 \%)$ & $76(38.2 \%)^{1}$ & 0.14 \\
\hline $\begin{array}{l}\text { Were you calm during the } \\
\text { labor? }\end{array}$ & $76(29.8 \%)$ & $101(39.6 \%)$ & $78(30.6 \%)^{m}$ & $57(26.9 \%)$ & $82(38.7 \%)$ & $73(34.4 \%)^{n}$ & 0.64 \\
\hline $\begin{array}{l}\text { Did you feel abandoned } \\
\text { during the labor? }\end{array}$ & $18(7.8 \%)$ & $59(25.5 \%)$ & $154(66.7 \%)^{\circ}$ & $10(5.2 \%)$ & $52(27.1 \%)$ & $130(67.7 \%)^{\mathrm{P}}$ & 0.56 \\
\hline $\begin{array}{l}\text { Were you afraid during the } \\
\text { labor? }\end{array}$ & $69(27.2 \%)$ & $91(35.8 \%)$ & $94(37.0 \%)^{q}$ & $57(27.1 \%)$ & 68 (32.4\%) & $85(40.5 \%)^{r}$ & 0.69 \\
\hline $\begin{array}{l}\text { Did you feel as if you had } \\
\text { no control over the labor? }\end{array}$ & $46(18.9 \%)$ & $117(48.1 \%)$ & $80(32.9 \%)^{5}$ & $41(21.5 \%)$ & $83(43.5 \%)$ & $67(35.1 \%)^{\mathrm{t}}$ & 0.61 \\
\hline $\begin{array}{l}\text { Are you satisfied with the } \\
\text { procedure? }\end{array}$ & $81(32.8 \%)$ & 123 (49.8\%) & $43(17.4 \%)^{\mathrm{u}}$ & 74 (35.2\%) & $108(46.8)$ & $28(13.3 \%)^{v}$ & 0.48 \\
\hline
\end{tabular}

${ }^{\mathrm{a}} 6.2 \%$ ( 17 of 273 women) missing.

${ }^{b} 4.8 \%$ (11 of 229 women) missing.

' $24.5 \%$ (67 of 273 women) missing.

${ }^{\mathrm{d}} 21.4 \%$ (49 of 229 women) missing.

e $4.8 \%$ ( 13 of 273 women) missing.

${ }^{5} .7 \%$ ( 13 of 229 women) missing.

${ }^{9} 5.1 \%$ (14 of 273 women) missing.

${ }^{\mathrm{h}} 7.0 \%$ (16 of 229 women) missing.

${ }^{i} 5.5 \%$ (15 of 273 women) missing.

j $4.4 \%$ (10 of 232 women) missing.

${ }^{\mathrm{k}} 12.5 \%$ ( 34 of 273 women) missing.

' $13.1 \%$ (30 of 229 women) missing.

$\mathrm{m}_{6} 6.6 \%$ (18 of 273 women) missing.

${ }^{\mathrm{n}} 7.4 \%$ (17 of 229 women) missing.

${ }^{\circ} 15.4 \%$ (42 of 273 women) missing.

${ }^{\mathrm{P}} 16.2 \%$ (37 of 229 women) missing.

${ }^{9} 7.0 \%$ ( 19 of 273 women) missing.

r $8.3 \%$ (19 of 229 women) missing.

${ }^{\mathrm{s}} 11.0 \%$ (30 of 273 women) missing.

${ }^{\mathrm{t}} 16.6 \%$ (38 of 229 women) missing.

u9.5\% (26 of 273 women) missing.

${ }^{v} 8.3 \%$ (19 of 229 women) missing.

nowadays, low-risk pregnancies go home after receiving a Foley catheter for induction of labor. Women's satisfaction and experiences with home induction would thereby be a very interesting perspective for further research.

In conclusion, induction of labor in women with an unfavorable cervix at term with oral misoprostol as compared with induction with Foley catheter generates comparable experiences. However, induction of labor with oral misoprostol seems to be the preferred method of induction for women because in the Foley catheter group, more women would prefer oral misoprostol in future inductions.

\section{Trial Registration Number}

The Netherlands Trial Register NTR3466, http://www.trialregister.nl. 


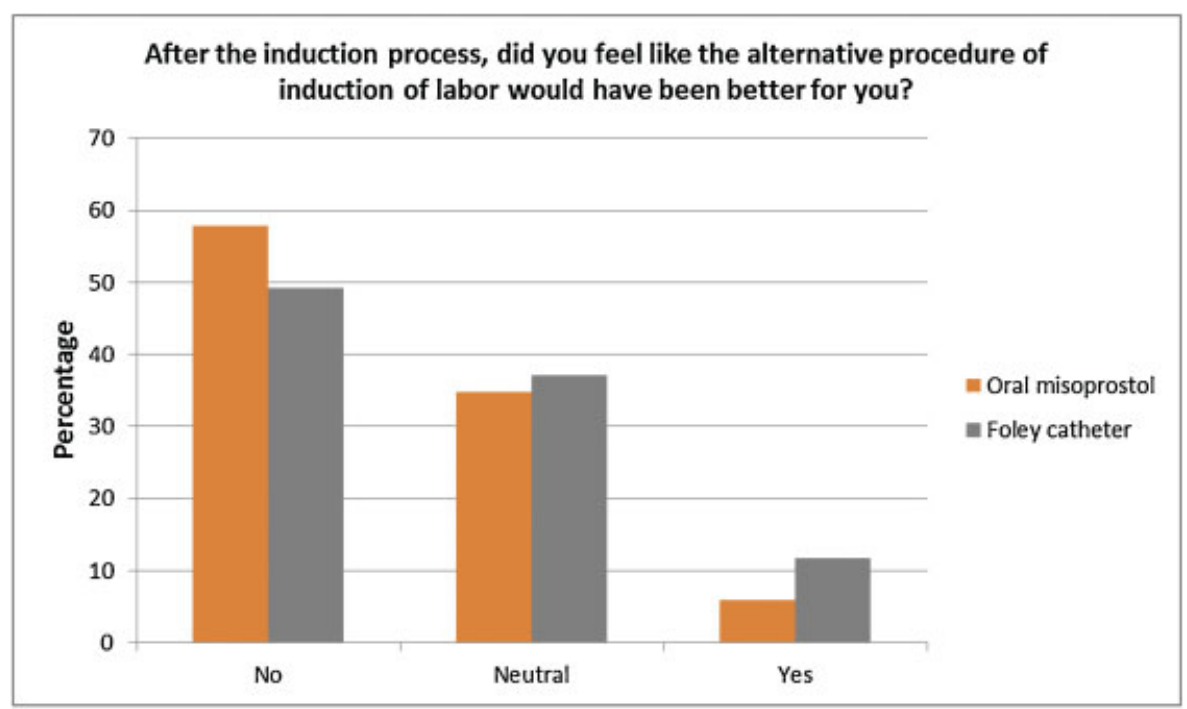

Fig. 2 Preference for induction method.

\section{Funding}

The PROBAAT-II study was partially funded by Fonds NutsOhra, a Dutch capital fund for health research and development.

\section{Conflict of Interest}

None.

\section{Acknowledgments}

The authors thank all the women who participated in this trial, and all participating institutions and their staff for their contribution to this study, particularly the research nurses and midwifes, and other recruiting staff for their excellent work. Furthermore, the authors would like to acknowledge Annemarie van der Velden, Librarian at Groene hart Ziekenhuis in Gouda, for helping them with the literature search. She has no conflict of interest and there was no source of compensation.

\section{References}

1 Perinataal Register Nederland. Perinatale zorg in Nederland 2013. Available at http://www.perinatreg.nl/uploads/150/153/PRN_jaarboek_2013_09122014.pdf. Accessed Feb 15, 2016

2 The Health and Social Car Information Centre. NHS Maternity Statistics, England 2013-2014. Available at http://www.hscic.gov. uk/catalogue/PUB16725/nhs-mate-eng-2013-14-summ-reporep.pdf. Accessed June 24, 2015

3 EURO-PERISTAT Project, with SCPE EUROCAT EURONEOSTAT. The European Perinatal Health Report 2010. Available at http://www. europeristat.com/reports/european-perinatal-health-report2010. Accessed June 24, 2015

4 NSW Public Health Bulletin: Mothers and Babies, NSW Department of Health. NSW Midwives Data Collection 2012. Available at http://www.health.nsw.gov.au/hsnsw/Publications/mothersand-babies-2012.pdf. Accessed October 10, 2015
5 Hildingsson I, Karlström A, Nystedt A. Women's experiences of induction of labour-findings from a Swedish regional study. Aust N Z J Obstet Gynaecol 2011;51(2):151-157

6 Jozwiak M, Bloemenkamp KW, Kelly AJ, Mol BW, Irion O, Boulvain M. Mechanical methods for induction of labour. Cochrane Database Syst Rev 2012;3:CD001233. Doi: 10.1002/14651858.CD00 1233.pub2

7 Alfirevic Z, Keeney E, Dowswell T, et al. Labour induction with prostaglandins: a systematic review and network meta-analysis. BMJ 2015;350:h217. Doi: 10.1136/bmj.h217

8 Ten Eikelder ML, Oude Rengerink K, Jozwiak M, et al. Induction of labour at term with oral misoprostol versus a Foley catheter (PROBAAT-II): a multicentre randomised controlled non-inferiority trial. Lancet 2016;387(10028):1619-1628

9 Ten Eikelder ML, Neervoort F, Oude Rengerink K, et al. Induction of labour with a Foley catheter or oral misoprostol at term: the PROBAAT-II study, a multicentre randomised controlled trial. BMC Pregnancy Childbirth 2013;13:67. Doi: 10.1186/1471-2393-13-67

10 Wijma K, Wijma B, Zar M. Psychometric aspects of the W-DEQ; a new questionnaire for the measurement of fear of childbirth. J Psychosom Obstet Gynaecol 1998;19(2):84-97

11 Garthus-Niegel S, Størksen HT, Torgersen L, Von Soest T, EberhardGran M. The Wijma Delivery Expectancy/Experience Questionnaire: a factor analytic study. J Psychosom Obstet Gynaecol 2011; 32(3):160-163

12 Gärtner FR, Freeman LM, Rijnders ME, et al. A comprehensive representation of the birth-experience: identification and prioritization of birth-specific domains based on a mixed-method design. BMC Pregnancy Childbirth 2014;14:147. Doi: 10.1186/ 1471-2393-14-147

13 Simkin P. The experience of maternity in a woman's life. J Obstet Gynecol Neonatal Nurs 1996;25(3):247-252

14 Shetty A, Burt R, Rice P, Templeton A. Women's perceptions, expectations and satisfaction with induced labour-a questionnaire-based study. Eur J Obstet Gynecol Reprod Biol 2005;123(1): 56-61

15 Sujata B, Iqbal V, Das A et al. Evaluation of non-pharmacological method-transcervical Foley catheter to intravaginal misoprostol and Prostaglandin E2 gel for preinduction cervical ripening. Biomedical Research 2012;2(23):247-252

16 Nuutila M, Halmesmäki E, Hiilesmaa V, Ylikorkala O. Women's anticipations of and experiences with induction of labor. Acta Obstet Gynecol Scand 1999;78(8):704-709 
146 Women's Experiences with and Preference for Induction of Labor ten Eikelder et al.

17 Jonsson M, Hellgren C, Wiberg-Itzel E, Akerud H. Assessment of pain in women randomly allocated to speculum or digital insertion of the Foley catheter for induction of labor. Acta Obstet Gynecol Scand 2011;90(9):997-1004
18 Ugwu EO, Onah HE, Obi SN, et al. Effect of the Foley catheter and synchronous low dose misoprostol administration on cervical ripening: a randomised controlled trial. J Obstet Gynaecol 2013; 33(6):572-577 